УДК 1

DOI $10.21661 / \mathrm{r}-130119$

\author{
С.Н. Баранов
}

КОНТАКТНАЯ ТРЕМОРОМЕТРИЯ И КОНТАКТНАЯ

КООРДИНАЦИОНОМЕТРИЯ ПО ПРОФИЛЮ КАК МЕТОДЫ

ДИАГНОСТИКИ ТОЧНОСТИ ДВИЖЕНИЯ РУК, НАРУШЕНИЙ НЕРВНОЙ СИСТЕМЫ И ПСИХИЧЕСКОГО СОСТОЯНИЯ ЧЕЛОВЕКА

Аннотация: в данной статье рассмотрены такие методики диагностики координачии, как «Контактная треморометрия» и «Контактная координациометрия по профилю». Данные методики позволяют оченить степень точности движения рук, а также могут использоваться в целях оченки нарушений нервной системы и психических состояний человека.

Ключевые слова: треморометрия, координациометрия, диагностика, точность движений.

\title{
S.N. Baranov
}

\section{CONTACT TREMOROMETRY AND CONTACT}

COORDINATIONOMETRY ON THE PROFILE AS DIAGNOSTIC METHODS FOR THE ACCURACY OF HAND MOVEMENTS, DISTURBANCES OF HUMAN NERVOUS SYSTEM AND MENTAL STATE

Abstract: this article describes such methods of coordination diagnostics as «Contact tremorometry» and «Contact coordinate profile along the profile». These techniques allow you to assess the degree of accuracy of hand movements, and they can also be used to assess the disorders of the nervous system and mental states of a person.

Keywords: tremorometry, coordinationiometry, diagnostics, accuracy of movements.

Как в мировой, так и в отечественной науке и практике интерес к психологии и к психологическим аспектам различных сфер жизнедеятельности человека 
не прекращает расти и по сей день. Одной из важнейших областей психологической практики является диагностика всевозможных психических явлений, т.е. устойчивых индивидуальных особенностей и текущих состояний человека.

Так психологические методики диагностики «Контактная треморометрия» и «Контактная координационометрия по профилю» используются для измерения точности управления движениями при решении двигательных задач [1]. Координация обуславливается согласованностью и соразмерностью движений человека. Исходя из того, что нервная система обеспечивает управление движениями тела человека, а также осуществляет сенсорный контроль за этими движениями способность человека к координации обусловлена текущими и константными особенностями нервной системы.

Но на двигательную координацию также может влиять и состояние опорнодвигательного аппарата и его физиологические особенности [3]. Именно поэтому при использовании методик «Контактная треморометрия» и «Контактная координационометрия по профилю» не следует делать однозначных выводов о состоянии нервной системы и ее свойствах, а также о текущем функциональном состоянии обследуемого в целом.

При диагностике координации по методикам «Контактная треморометрия» и «Контактная координационометрия по профилю» в качестве специальных приборов используется следующее:

- специальная платформа (пластина) с тремя отверстиями различного диаметра и лабиринтом;

- стержень («щуп»).

При обследовании по методике «Контактная треморометрия» обследуемому необходимо вставить алюминиевый стержень («щуп») в одно из отверстий платформы и продержать его в отверстии в течение заданного времени, не касаясь краев отверстия. Рекомендуемая продолжительность обследования составляет 15 секунд.

При обследовании по методике «Контактная координационометрия по профилю» - вставить алюминиевый стержень через одно из отверстий платформы в 
начало лабиринта на глубину 2-3 мм и как можно быстрее провести концом стержня до конца лабиринта, стараясь не касаться краев отверстия.

Рука обследуемого, которой он держит «щуп» должна находиться на весу, выпрямлена в локтевом суставе. В случае касания краев отверстия либо лабиринта алюминиевым стержнем, подается световой сигнал.

Во время обследования (методика «Контактная треморометрия») регистрируются такие показатели, как количество касаний стержнем боковых стенок отверстия (регистрация непроизвольных отклонений от заданной точки), а также общая продолжительность данных касаний (таблица 1). В обследованиях по методике «Контактная координационометрия по профилю» рассчитываются среднее число и средняя продолжительность касаний в секунду, с учетом времени прохождения лабиринта (таблица 2).

Таблица 1

Интерпретациия результатов обследований по методике «Контактная треморометрия» [1]

\begin{tabular}{|c|c|c|c|}
\hline № & Показатель & $\begin{array}{c}\text { Диагностируемое } \\
\text { свойство }\end{array}$ & Интерпретация \\
\hline \multirow[b]{2}{*}{1} & \multirow{2}{*}{$\begin{array}{l}\text { Среднее количество } \\
\text { касаний в секунду }\end{array}$} & $\begin{array}{l}\text { Мануальный тре- } \\
\text { мор }\end{array}$ & $\begin{array}{l}\text { Чем больше число касаний в секунду, } \\
\text { тем выше частота и амплитуда тремора }\end{array}$ \\
\hline & & Координация & $\begin{array}{l}\text { Чем больше число касаний в секунду, } \\
\text { тем меньше степень выраженности спо- } \\
\text { собности к координации движений }\end{array}$ \\
\hline 2 & $\begin{array}{l}\text { Средняя продолжи- } \\
\text { тельность касаний в } \\
\text { секунду }\end{array}$ & $\begin{array}{l}\text { Сенсорный кон- } \\
\text { троль над движени- } \\
\text { ями }\end{array}$ & $\begin{array}{l}\text { Чем больше средняя продолжитель- } \\
\text { ность касаний в секунду, тем ниже сте- } \\
\text { пень сенсорного контроля над движени- } \\
\text { ями }\end{array}$ \\
\hline
\end{tabular}

Таблица 2

Интерпретация результатов обследований по методике «Контактная координацчионометрия по профилю» [1]

\begin{tabular}{|c|l|l|l|}
\hline № & \multicolumn{1}{|c|}{ Показатель } & $\begin{array}{c}\text { Диагностируемое } \\
\text { свойство }\end{array}$ & \multicolumn{1}{c|}{ Интерпретаичя } \\
\hline 1 & $\begin{array}{l}\text { Среднее количество } \\
\text { касаний в секунду }\end{array}$ & Мануальный тремор & $\begin{array}{l}\text { Чем больше число касаний в секунду, } \\
\text { тем выше частота и амплитуда тре- } \\
\text { мора }\end{array}$ \\
\hline
\end{tabular}




\begin{tabular}{|l|l|l|l|}
\hline & Координация & $\begin{array}{l}\text { Чем больше число касаний в секунду, } \\
\text { тем меньше степень выраженности } \\
\text { способности к координации движений }\end{array}$ \\
\hline 2 & $\begin{array}{l}\text { Средняя продолжи- } \\
\text { тельность касаний в } \\
\text { секунду }\end{array}$ & $\begin{array}{l}\text { Сенсорный кон- } \\
\text { троль над движени- } \\
\text { ями }\end{array}$ & $\begin{array}{l}\text { Чем больше средняя продолжитель- } \\
\text { ность касаний в секунду, тем ниже } \\
\text { степень сенсорного контроля } \\
\text { над движениями }\end{array}$ \\
\hline $\begin{array}{l}\text { Время прохождения } \\
\text { лабиринта }\end{array}$ & $\begin{array}{l}\text { Подвижность нерв- } \\
\text { ных процессов } \\
\text { хождения лабиринта диагностируется } \\
\text { инертность нервных процессов обсле- } \\
\text { дуемого, при низких - подвижность }\end{array}$ \\
\hline
\end{tabular}

После проведенного обследования по методике «Контактная треморометрия» или «Контактная координационометрия по профилю» указывается степень точности движений обследуемого. Высокая точность движений диагностируется при низких показателях количества и продолжительности касаний, низкая - при высоких показателях.

Перечисленные выше методики в основном используются в целях профессионального отбора на специальности, где в процессе осуществления профессиональной деятельности необходима высокая точность движений рук [2]. К тому же данные методики могут быть использованы для диагностики нарушений нервной системы и психических состояний в сочетании с другими методами диагностики.

\section{Список литературы}

1. Мантрова И.Н. Методическое руководство по психофизиологической и психологической диагностике. - Иваново: ООО «Нейрософт», 2007.

2. Старостин О.А. Коррекция нарушений психофизиологических функций у специалистов опасных профессий путем сочетанного использования разномодальных физических факторов / О.А. Старостин, А.Г. Соловьев, Ю.Е. Барачевский, Р.Б. Мусаев // Экология человека. - 2012. - Вып. №5.

3. Цветков С.А. Коррекция функционального состояния и работоспособности биатлонистов / С.А. Цветков, Ю.Ф. Кашкаров, Ф.М. Соколова // Ученые записки университета им. П.Ф. Лесгафта. - 2014. - Вып. №12 (118). 
4. Ланская О.В Особенности нейродинамических свойств и качества жизни спортсменов с травмами и посттравматическими заболеваниями опорно-двигательного аппарата [Электронный ресурс]. - Режим доступа: http://novainfo.ru/article/9159 (дата обращения: 14.04.2017).

Баранов Сергей Николаевич - магистрант кафедры анатомии и физиологии человека ФГБОУ ВО «Курганский государственный университет», Россия, Курган.

Baranov Sergey Nikolaevich - graduate student of the Department of Human Anatomy and Physiology FSFEI of HE "Kurgan State University”, Russia, Kurgan. 